\title{
Muscarinic Receptor Binding
}

National Cancer Institute

\section{Source}

National Cancer Institute. Muscarinic Receptor Binding. NCI Thesaurus. Code C40521.

A process that involves the non-covalent interaction of acetylcholine with one of the five muscarinic receptors. These interactions play a role in signal transduction, which influences bodily functions including salivation, lacrimation, urination, digestion and defecation. 